\title{
ENSAIO FOTOGRÁFICO Caranguejos, caranguejeiros e seus movimentos
}

\author{
Lucas Coelho Pereira ${ }^{1}$ \\ Universidade de Brasília
}

Resumo: O Delta do Rio Parnaíba é o maior das Américas em mar aberto. Os manguezais dessa região são considerados, por caranguejeiros e outros pesquisadores, extremamente importantes para humanos e não humanos viventes no estuário. A presente narrativa visual busca se aproximar dos mangues do Delta a partir das caminhadas de catadores de caranguejo em seus cotidianos de trabalho. A ideia é mostrar como o simples ato de caminhar no mangue compreende um conhecimento complexo a respeito dos manguezais, dos caranguejos e várias outras formas de vida.

Palavras-chave: manguezais; caranguejos; comunidades tradicionais; conhecimento ecológico. 


\title{
Crabs, crab workers and their movements
}

\begin{abstract}
The Parnaíba River Delta is the largest in the Americas in the open sea. The mangroves in this region are considered, by crab scavengers and other researchers, to be extremely important for humans and non-humans living in the estuary. The present visual narrative seeks to approach the Delta mangroves from the walks of crab scavengers in their daily work. The idea is to show how the simple act of walking in the mangrove comprises complex knowledge about mangroves, crabs, and various other forms of life.
\end{abstract}

Keywords: mangroves; crabs; traditional communities; ecological knowledge.

\section{Cangrejos, cangrejeros y sus movimientos}

Resumen: El delta del río Parnaíba es el más grande de América en mar abierto. Los manglares en esta región son considerados, por los carroñeros de cangrejos y otros investigadores, extremadamente importantes para los humanos y no humanos que viven en el estuario. La presente narrativa visual busca acercarse a los manglares del Delta desde los paseos de los carroñeros de cangrejos en su trabajo diario. La idea es mostrar cómo el simple acto de caminar en el manglar comprende un conocimiento complejo sobre los manglares, los cangrejos y otras formas de vida.

Palabras clave: manglares; cangrejos; comunidades tradicionales; conocimiento ecológico. 
66 Tudo no mundo tem que ficar sabido, porque se não se acaba”. Foi assim que um antigo caranguejeiro no Delta do Rio Parnaíba me justificou as artimanhas dos caranguejos com o mangue e seus predadores humanos. Esses crustáceos raramente vivem em buracos retilíneos. Fazem voltas, escondem-se em cavernas de terra sob o solo - os rebancos - e até largam as patas quando se veem terrivelmente ameaçados. Para os catadores, se isso não é prova da inteligência desses bichos, o que seria?

A esperteza dos caranguejos - expressa em suas práticas de habitação nos manguezais - requer dos caranguejeiros habilidades e movimentações específicas para capturá-los. Além disso, o próprio ato de adentrar o mangue envolve-os em relações que considerem a agência de viventes diversos - para além do caranguejo. As andanças e movimentações dos meus anfitriões, portanto, falam-nos de formas corporificadas de conhecer e interagir com outros mais que humanos. Aqui, a ideia é seguir diferentes momentos do caminhar de Querido, Luiz, Antônio João, Lelía e Zito, os protagonistas desta narrativa.

As imagens fazem parte do meu trabalho de doutorado, desenvolvido pelo Departamento de Antropologia da Universidade de Brasília. A pesquisa de campo foi realizada ao longo de doze meses entre os anos de 2018 e 2020 em áreas adjacentes e internas à Reserva Extrativista Marinha do Delta do Parnaíba. A presente investigação integra um projeto de pesquisa mais amplo - "Ecologia política da pesca de crustáceos em manguezais no nordeste brasileiro" - realizado pela Fundação Joaquim Nabuco (MEC).

Recebido em 19 de março de 2020.

Aceito em 8 de agosto de 2020. 


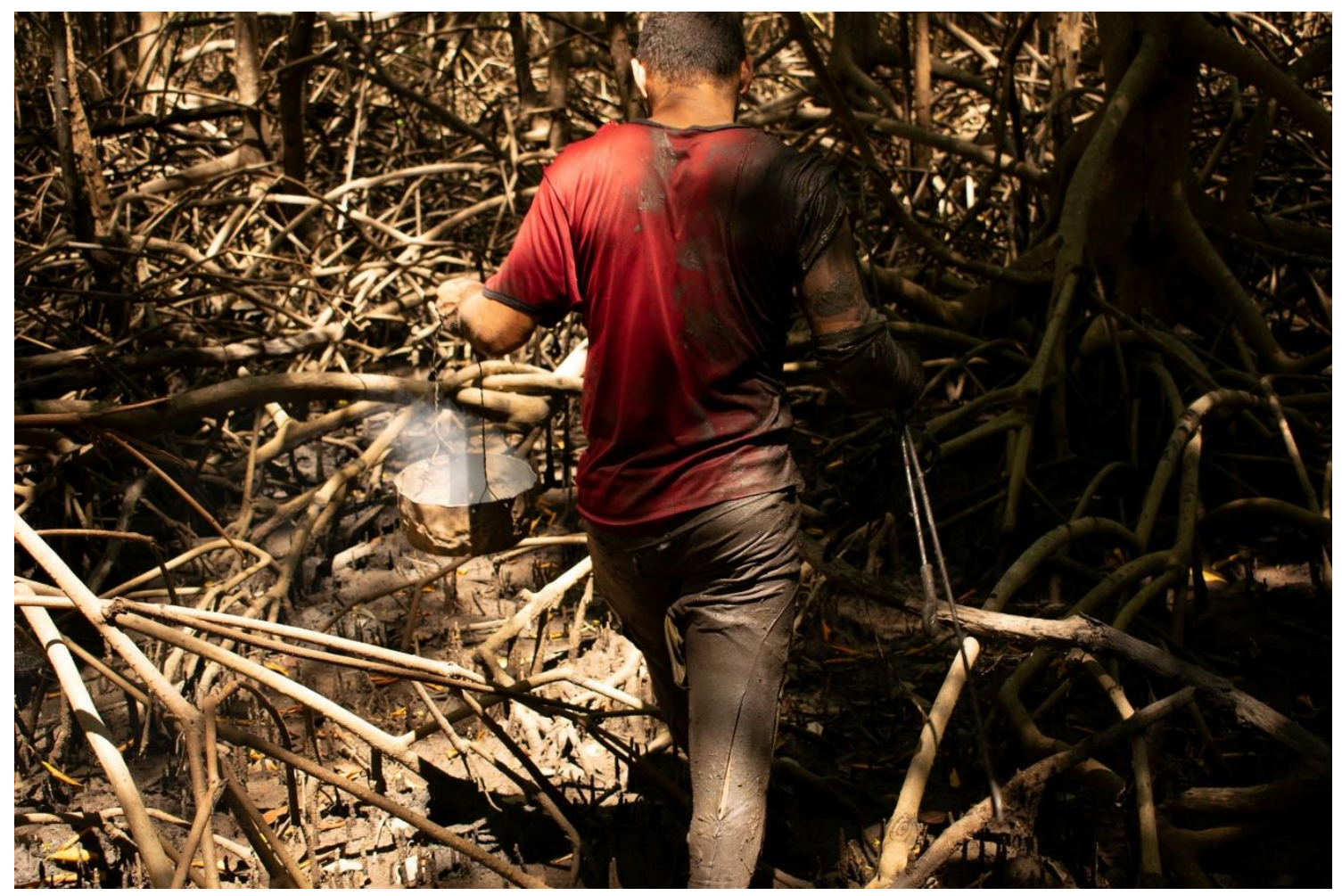

Foto 1 - Adentrar o mangue requer cuidado e atenção. É preciso usar fumaça para proteger-se de insetos, equilibrar o peso do corpo e vasculhar o espaço com os olhos. Há caranguejos por toda parte, o desafio é localizá-los. Na imensidão do mangal, eles se fazem visíveis através de pistas deixadas na lama. 

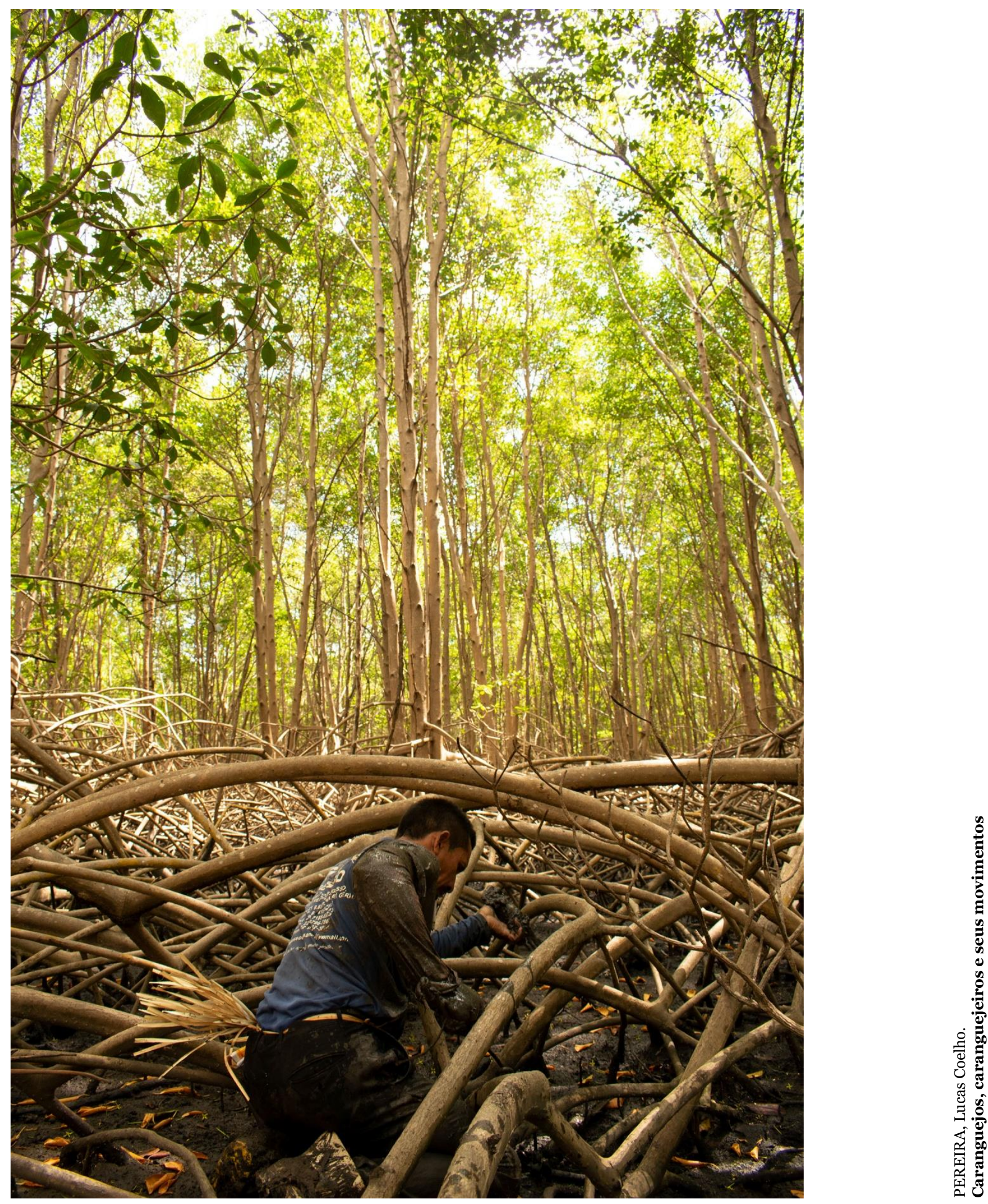

Foto 2 - Pegar caranguejo é um trabalho solitário. Ainda que diversos catadores se preparem em turmas, eles se separam ao entrar no mangue. Preferem andar por lugares sem pegadas de botas. As movimentações de seu Luiz, portanto, consideram não só os rastros dos caranguejos, mas também dos parceiros humanos. 


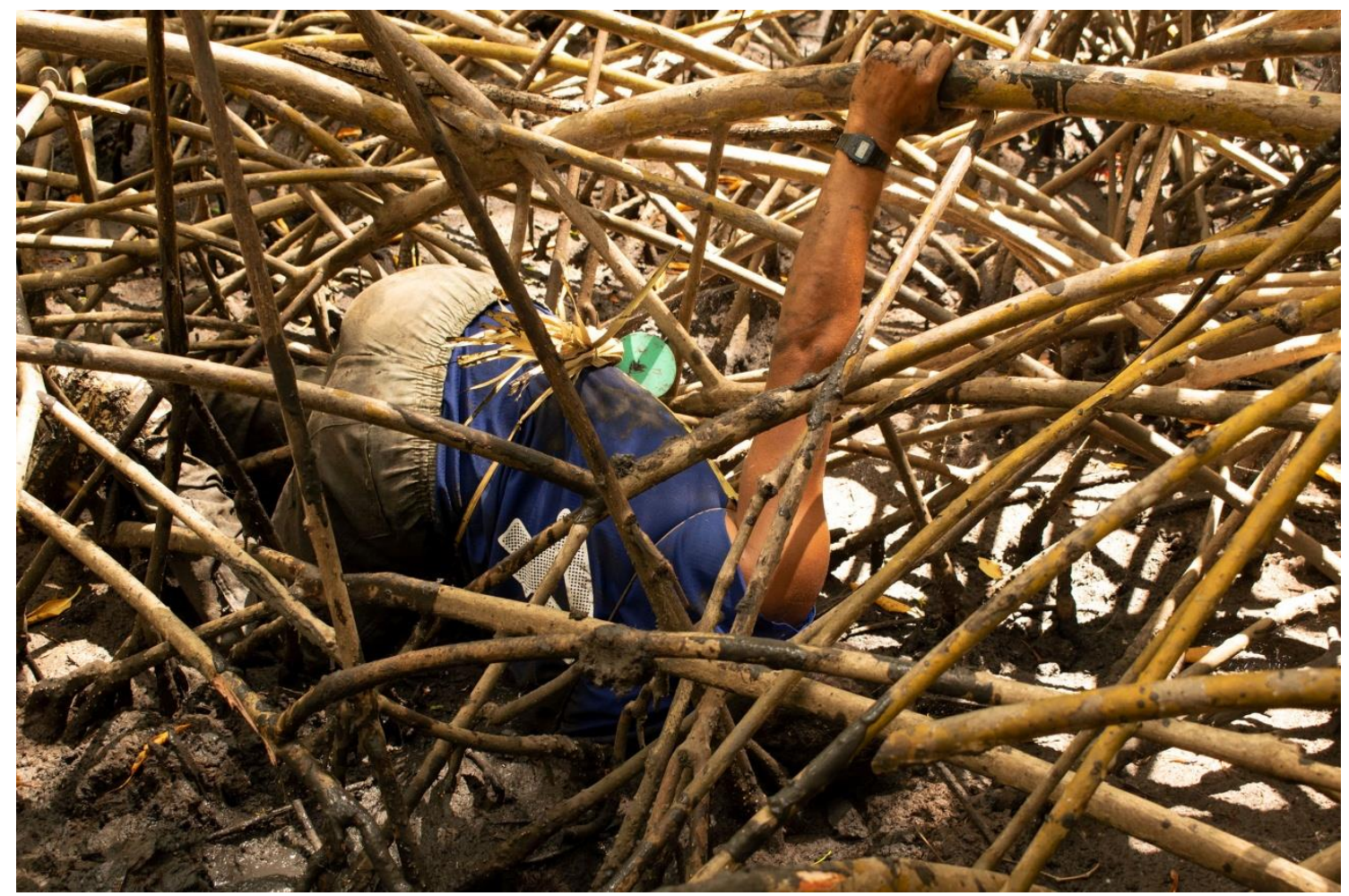

Foto 3 - Sob o solo, o braço de Antônio João percorre outros labirintos. Quando o caranguejo faz morada em locais de difícil acesso, diz-se que ele está (ou é) “enrascado”. Situações assim são comuns. Não por acaso, comuns também são as reclamações de dores nas costas, na lombar e nos nervos das mãos. 


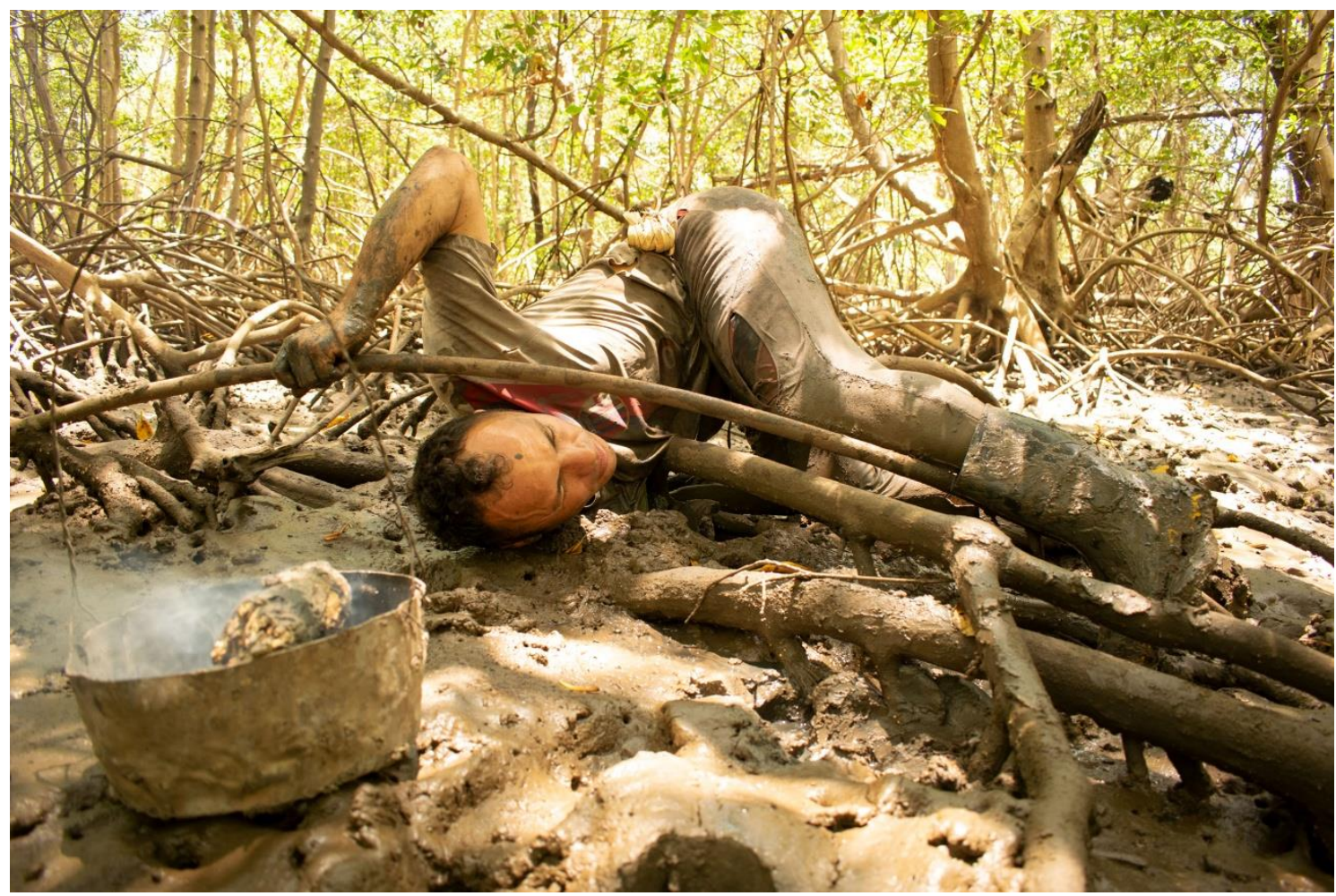

Foto 4 - Querido me contou de como os caranguejos estão cada vez mais fundos. Acossados, eles se escondem - falou. Há cerca de vinte anos, era possível pegá-los só com o braço. Hoje, Querido e todos os outros se utilizam ainda do "cambito", um vergalhão de ferro cujo manuseio implica certos movimentos. 


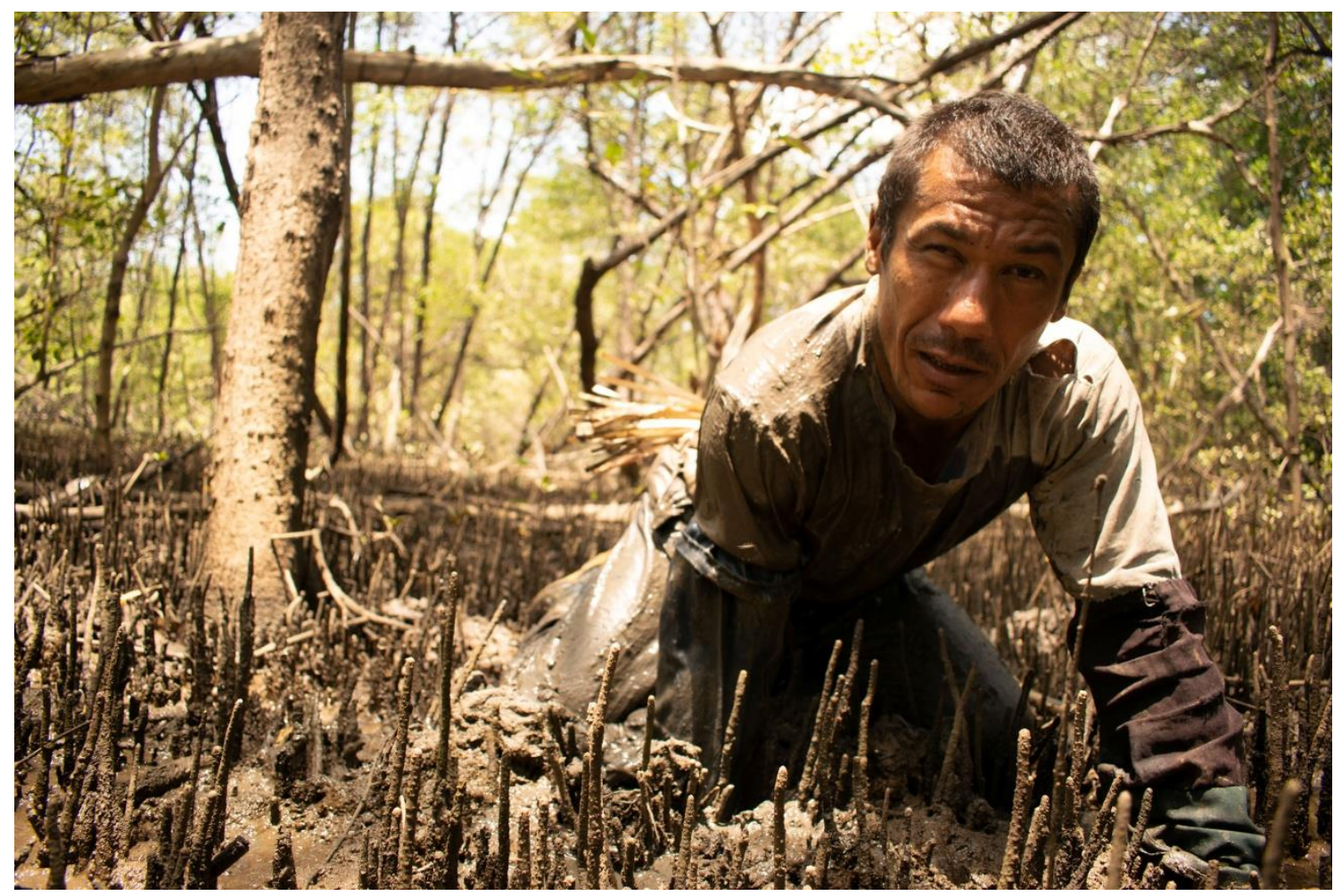

Foto 5 - Lelía me disse preferir mangues onde possa se movimentar mais livre. Em certos locais do Delta, há predominância do mangue siriba que, diferente do mangue vermelho, permite caminhar e capturar caranguejos sem que se tenha que lidar constantemente com o ato de se equilibrar nas raízes. 


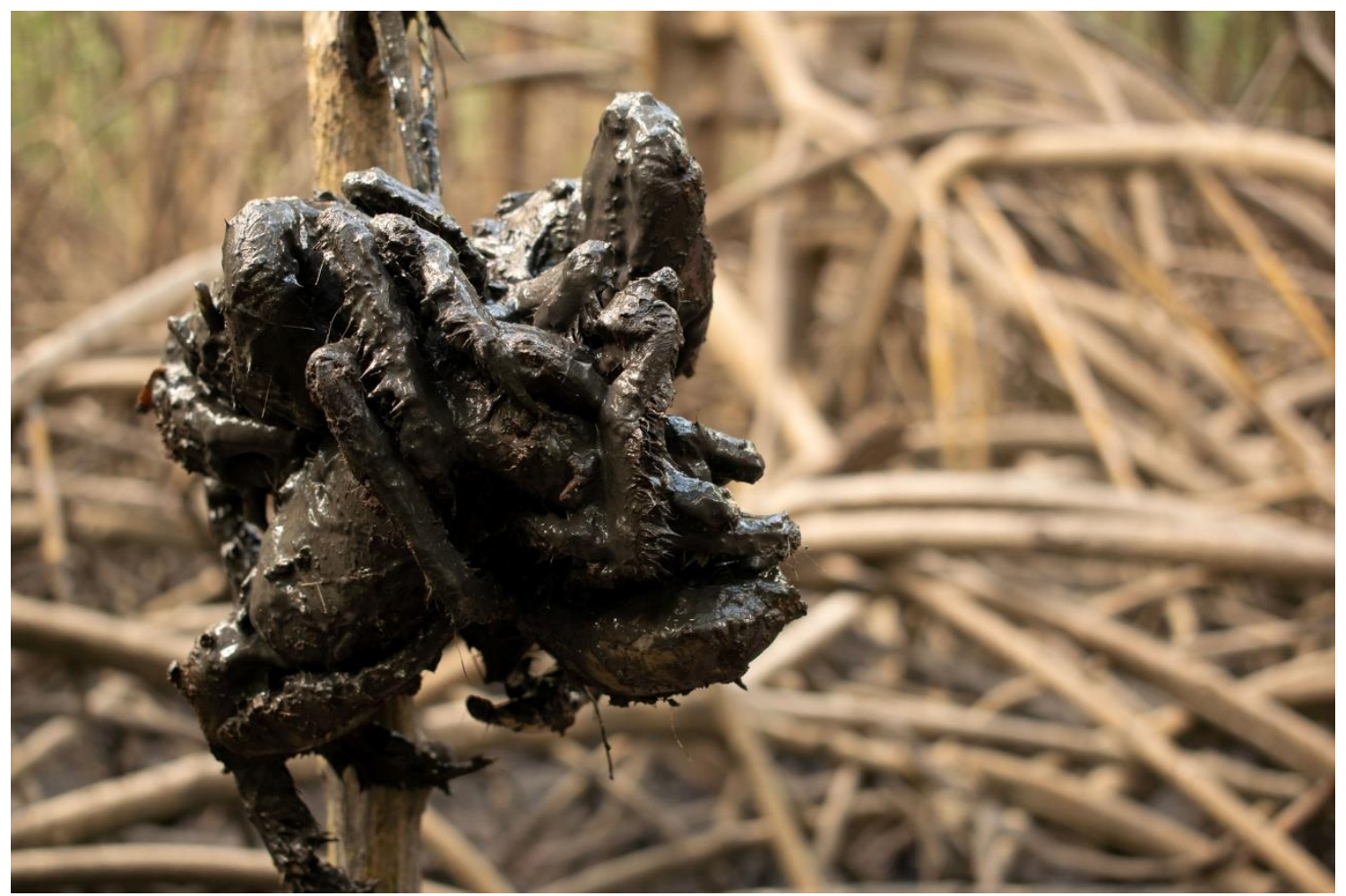

Foto 6 - No Delta do Parnaíba, o tamanho mínimo estabelecido pelos órgãos ambientais para a captura do caranguejouçá é de 6 centímetros em algumas áreas e 7 em outras. Pegar espécimes menores que isso, "pega mal” não só legalmente como também perante compradores, clientes e outros caranguejeiros. 


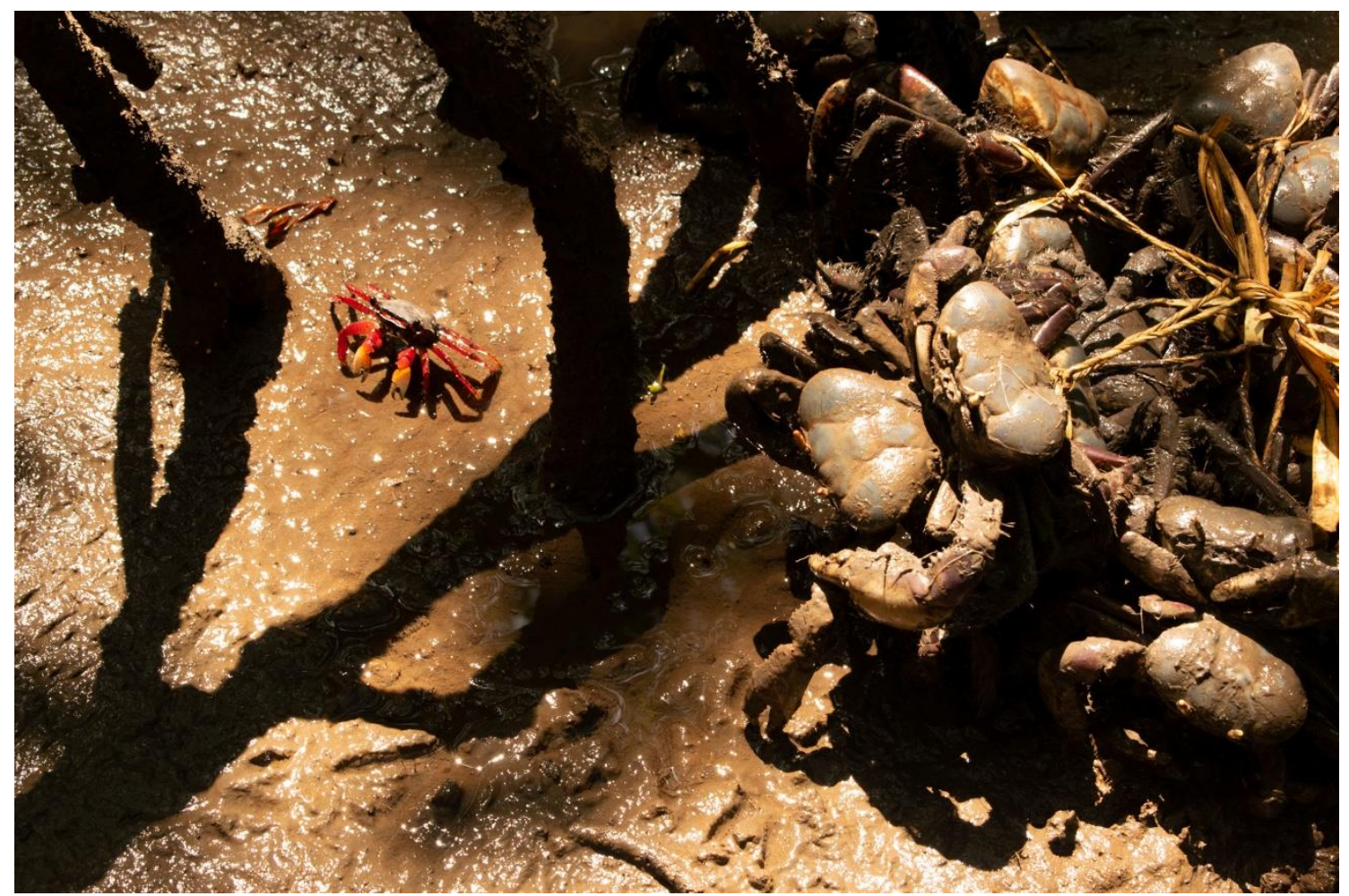

Foto 7 - Caranguejo é bicho perseguido. Além dos humanos, macacos-pregos, gaviões e inclusive outros crustáceos são grandes apreciadores de sua carne, como é o caso das corredeiras. Elas cavoucam feridas abertas nos caranguejos durante a captura, levando-os a morte antes mesmo de saírem do mangue. 


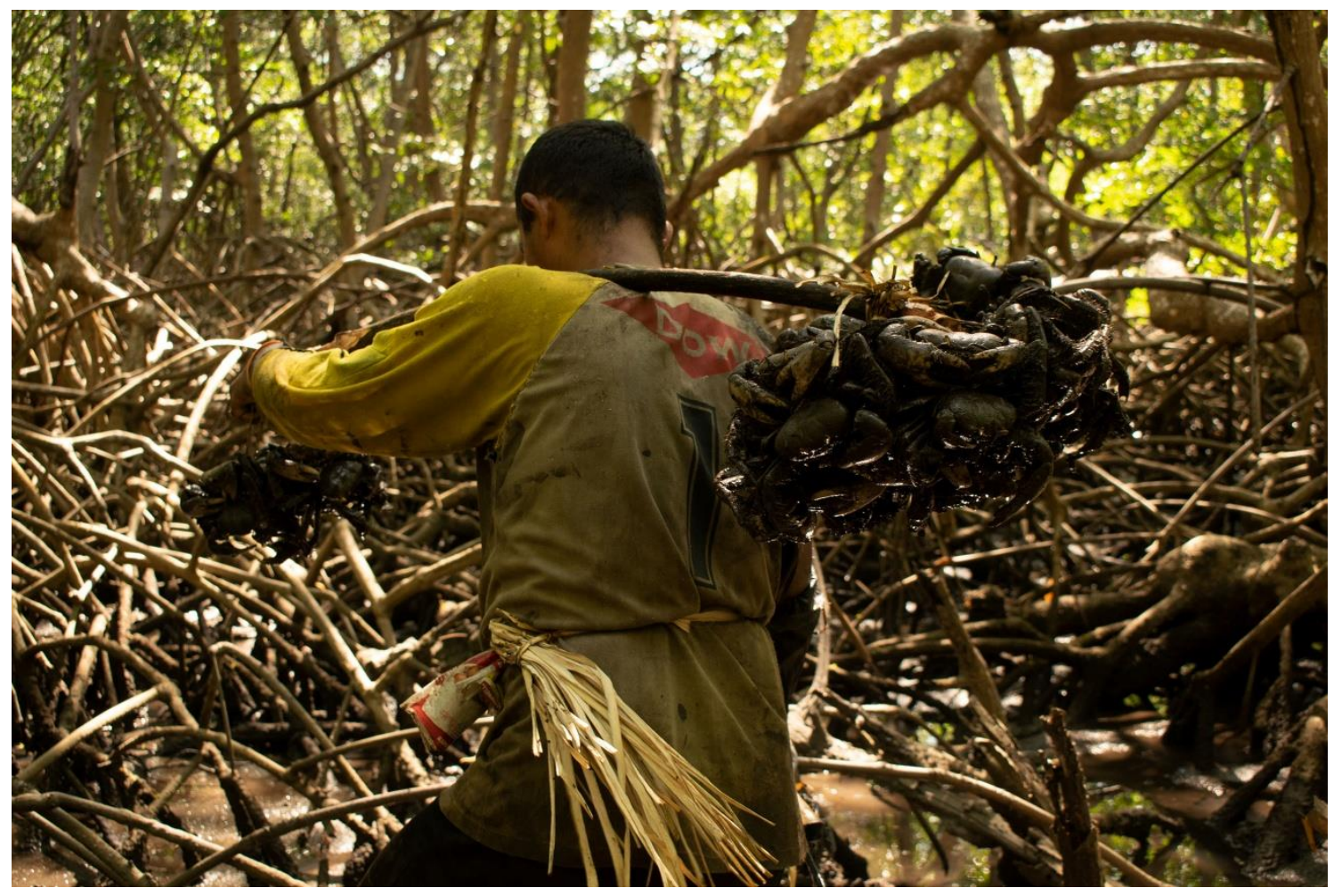

Foto 8 - O preço de uma corda - quatro caranguejos - depende do tamanho dos bichos, do local de venda e da época do ano. Nos meses de agosto a setembro, Zito, morador da periferia de Parnaíba-PI, venderia as 15 cordas capturadas por ele a 3,50 cada. 


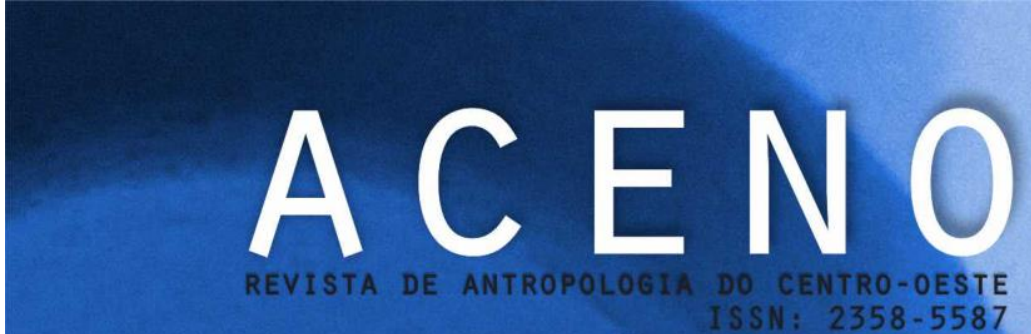

A Aceno recebe em FLUXO CONTÍNUO, artigos livres, resenhas, ensaios fotográficos, dossiês (propostas). Interessados em atuar como pareceristas

podem realizar seus cadastros no site 